\title{
REMANESCENTES DE CERRADOS, POVOS, TRADIÇÕES E A AMEAÇA DAS BARRAGENS DE PCHs
}

\author{
Valdir Specian ${ }^{1}$ \\ Fernando Uhlmann Soares ${ }^{2}$ \\ Sabrina Carlindo Silva ${ }^{3}$
}

Resumo: $O$ aumento da demanda por energia elétrica no Brasil a partir da década de 1990 e as crises de fornecimento (apagões) em 2001 e 2002 fez com que o governo brasileiro alterasse a política do setor elétrico brasileiro, fomentando, entre outras ações, a construção de pequenas centrais hidrelétricas (PCHs). As PCHs, construídas pela iniciativa privada, com o apoio de financiamento público desde de então se multiplicaram por todos os estados da federação. A tese de que uma $\mathrm{PCH}$ apresenta baixo impacto ambiental e socioeconômico se esvazia quando consideramos a quantidade de empreendimentos instalados e em operação. Neste artigo estão apresentados resultados das pesquisas envolvendo a construção e instalação de PCHs na Bacia do Rio Caiapó/GO e os impactos socioambientais associados. Os trabalhos de campo, o diálogo com moradores atingidos pela construção da PCHs e a análise documental permitiu verificar quais os impactos socioambientais provocados por esses empreendimentos.

Palavras-chave: Energia Elétrica; Populações Atingidas; Goiás.

\section{LES RESTES DU BIOME CERRADO, LES PEUPLES, LES TRADITIONS CULTURELLES ET LA MENACE DES PETITES CENTRALES HYDROELECTRIQUES}

\begin{abstract}
Abstrait: L'accroissement de la demande d'électricité au Brésil depuis les années 90 et les crises d'approvisionnement en énergie (coupure électrique) en 2001 et 2002 ont contraint l'État brésilien à modifier la politique du secteur de l'électricité, encourageant notamment la construction de petites centrales hydroélectriques (PCHs). Les PCHs, construites par l'initiative privée, avec le soutien de financements publics, se sont multipliés par tous les états de la fédération. La thèse selon laquelle une $\mathrm{PCH}$ a un faible impact socio-économique et sur l'environnement est réfuté lorsque l'on examine le nombre de projets mis en place et déjà en fonctionnement. Cet article présente les résultats de recherches portant sur la construction et l'installation de PCHs dans le bassin versant de Caiapó, dans l'état de Goiás (Brésil) et les impacts socio-environnementaux engendrés. Les travaux de terrain, le dialogue avec les habitants touchés par la construction de PCHs et l'analyse

\footnotetext{
${ }^{1}$ Docente do Curso de Geografia da Universidade Estadual de Goiás - Câmpus de Iporá; Doutorando do Programa de PósGraduação em Geografia da Universidade Federal de Goiás - Regional de Jataí. vspecian@ gmail.com

${ }^{2}$ Docente de Geografia do Instituto Federal Goiano - Câmpus de Rio Verde; Doutorando do Programa de Pós-Graduação em

${ }^{3}$ Docente de Geografia da Rede Pública do Estado de Goiás. Mestranda do Programa de Pós-Graduação em Geografia da Universidade Federal de Goiás - Regional de Jataí - sabrinacarlindoo@ gmail.com

Estudos Geográficos, Rio Claro, 17: 193-204, jan./jun. $2019 \quad$ (ISSN 1678-698X)
} Geografia da Universidade Federal de Goiás - Regional de Jataí. fernando.soares@ifgoiano.edu.br http://www.periodicos.rc.biblioteca.unesp.br/index.php/estgeo
\end{abstract}


documentaire ont permis de vérifier les impacts socio-environnementaux engendrés par ces projets.

Mots-clés: Énergie électrique; Populations touchées; État de Goiás.

\section{INTRODUÇÃO}

O setor de geração energia no Brasil passou por uma profunda mudança na década de 1990 com o processo de criação da Agência Nacional de Energia Elétrica (ANEEL) - agência criada através da Lei 9427/1996 ${ }^{4}$.

No caso específico das PCHs a Lei $\mathrm{n}^{0} 10.438 / 2002$ que cria o Programa de Incentivo às Fontes Alternativas de Energia Elétrica - PROINFA é um passo importante para estimulo do setor empresarial investir na produção de energia elétrica. Outro incentivo importante foi estabelecido com 0 decreto de regulamentação nำ5.025/2004 (BRASIL, 2004), neste decreto é instituído o fomento a empreendimentos autônomos de produção de energia elétrica, usando como justificativa a redução da emissão de gases de efeito estufa, nos termos da Convenção-Quadro das Nações Unidas sobre Mudança do Clima, contribuindo para o desenvolvimento sustentável (BRASIL, 2004). Essas e outras leis foram introduzidas para minimizar os impactos da crise energética brasileira.

O fomento para a rápida construção de novas unidades geradoras permitiu que as regras socioambientais básicas ficassem a margem da discussão do licenciamento. Dessa forma, os conflitos envolvendo a construção de PCHs se espalham pelo território nacional. Os mais recentes e que merecem destaque na mídia estão no vale do Rio Ribeira nos Estados do Paraná e São Paulo, região com a maior área continua de Floresta Atlântica preservada e local onde vivem povos tradicionais, sobretudo remanescentes de quilombos (ISA, 2018). Em Goiás além das bacias ocupadas com PCHs em funcionamento é previsto a construção desse tipo de empreendimento na região do Parque Nacional da Chapada dos Veadeiros, atingindo sobretudo as comunidades Kalunga que vivem na região - local conhecido com Vão de Almas.

No caso de Goiás a empresa que conseguiu a outorga para construção de PCHs na Região da Chapada dos Veadeiros é a RIALMA S/A - os proprietários têm parentesco com a atual governador do Estado, empossado em janeiro de 2019. Para tentar impedir a instalação das PCHs nos Rio das Almas e no Rio Tocantinzinho foi criado o movimento Chapada Zona Livre de PCHs.

Em outras regiões o processo de construção e instalação foi rápido e doloroso para as comunidades instaladas próxima aos rios, como o caso da $\mathrm{PCH}$ Santo Antônio do Caiapó - objeto de estudo apresentado nesse artigo.

Os conflitos provocados pela construção de barragens é algo antigo no Brasil. Zhouri e Oliveira (2007) relatam as consequências da privatização do setor elétrico brasileiro e o avanço das empresas transnacionais sobre o território brasileiro, sobretudo em áreas ricas em minérios e destacam:

O resultado dessa dinâmica é a intensificação do uso de áreas economicamente marginais e a expansão da fronteira econômica do

\footnotetext{
${ }^{4}$ A criação da ANEEL é parte de uma política de reforma de estado, foram criadas outras agências controladoras. Esse processo começa antes no governo Collor (1990) com a política de desestatização da economia. A lógica neoliberal foi colocada no processo político/econômico brasileiro.

Estudos Geográficos, Rio Claro, 17: 193-204, jan./jun. $2019 \quad$ (ISSN 1678-698X) http://www.periodicos.rc.biblioteca.unesp.br/index.php/estgeo
} 
mercado sob territórios historicamente ocupados por agricultores familiares e minorias étnicas. Nessa medida, o que se tem é a conformação de zonas de conflito onde as assimetrias de poder que atravessam as relações entre os segmentos em disputa resvalam em processos violentos de expropriação das populações locais. Frente à organização de unidades de mobilização e resistência, setores do Estado brasileiro não raramente têm respondido às denúncias e reivindicações locais com ações repressoras. (ZHOURI e OLIVEIRA, 2007, p. 121).

O objetivo desse artigo é de apresentar e discutir as consequências socioambientais provocadas pela construção das PCHs. Considerando que na maioria das vezes às áreas atingidas e o número de famílias prejudicadas em cada empreendimento é baixo em relação às grandes obras de geração de energia (UHE), o assunto é pouco debatido na sociedade.

Neste artigo são apresentados, de forma pontual, as intervenções provocadas pela construção da PCH Santo Antônio do Caiapó, essa usina pertencente ao Grupo Rialma S/A, foi instalada no rio de mesmo nome (Caiapó), um afluente do rio Araguaia em área limítrofe dos municípios de Ivolândia, Arenópolis e Palestina de Goiás/GO.

\section{MATRIZ ENERGÉTICA BRASILEIRA E O AVANÇO DA PCHS}

Segundo a ANEEL (2017), no Brasil a técnica hidráulica ou hídrica é a mais utilizada, sendo responsável por mais de $64 \%$ da geração de energia elétrica do país, esse dado mostra a importância que as bacias hidrográficas têm para o Brasil. Do total de $64 \%$ da geração, as $\mathrm{PCH}$ respondem por apenas 3,26\% do total da matriz hidroenergética, são contabilizadas 445 PCHs em operação no Brasil (ANEEL, 2017).

No estado de Goiás várias bacias hidrográficas estão sendo utilizadas para a produção de energia elétrica através da implantação das $\mathrm{PCHs}$. Destaque-se para a Bacia do Rio Caiapó que tem previsão de absorver $12 \mathrm{PCHs}$, sendo que quatro (4) já estão em funcionamento. Na região do Parque Nacional das Chapada dos Veadeiros e nas Comunidades Kalunga estão previstas a construção de 22 PCHs (ANEEL, 2017).

Em 2018 Goiás contava com 23 PCHs, sendo que 22 delas estavam em operação e 1 em construção. A tabela 1 apresenta o total de PCHs situadas no estado de Goiás, considerando as PCHs em operação, construção e em licenciamento.

Estudos Geográficos, Rio Claro, 17: 193-204, jan./jun. $2019 \quad$ (ISSN 1678-698X) http://www.periodicos.rc.biblioteca.unesp.br/index.php/estgeo 
Tabela 1 - Quantidade de PCHs em operação, construções e em processo de licenciamento no estado de Goiás

\begin{tabular}{|l|c|r|}
\hline \multicolumn{2}{|c|}{ Investimento em PCH no Estado de Goiás } \\
\hline \multicolumn{1}{|c|}{ Tipo } & Quantidade & Potência outorgada (kW) \\
PCHs em Operação & 22 & 420.014 \\
PCHs em Construção & 1 & 29.300 \\
PCHs previsão de & 6 & 128.607 \\
construção (licenciamento) & & \\
\hline
\end{tabular}

Fonte: ANEEL, 2017.

Organizado pelos autores.

\section{HISTÓRICO DE OCUPAÇÃO DE CERRADO: OS NOVOS ATORES E OS CONFLITOS AGRARIOS PELA ÁGUA}

A leitura das obras que discutem a ocupação do Cerrado Goiano apresentam uma realidade de um território esparsamente ocupado até meados do século XX. Goiás ficava distante dos principais centros de comercialização e consumo do Brasil. Nessa perspectiva Borges (2016) chama o processo e as relações socioeconômicas e políticas da ocupação do sertão goiano como Fazendaroça goiana e descreve:

Após recortada e ampliada, entendemos que a Fazenda-roça goiana consiste na organização espacial que comandou Goiás por aproximadamente dois séculos, final do século XVIII a meados do século XX. Essa organização representa a interação dos elementos internos e externos que de forma dialética a particulariza e a integra à condição espacial brasileira e mundial da época (BORGES, 2016 p. 33 e 34).

Como destaca Borges $(2007 ; 2016)$, a história de Goiás começa a mudar a partir de meados do século $\mathrm{XX}$, um fator importante para esse processo está relacionado à construção de Brasília e a necessidade da modernização do território goiano, transformando uma "rentabilidade simples e lenta a uma rentabilidade liberal, inteligente, planejada". Antes disso, destacam-se, ainda dois eventos importantes nas décadas de 1930/1940 - a Marcha para Oeste ${ }^{5}$ e a Construção da nova capital do Estado - Goiânia (FREITAS E CHAVEIRO, 2011).

Mendonça (2004) destaca a importância da construção de Brasília e a introdução de eixos rodoviários ligando o Brasil a nova capital, além de uma séries de outras ações, que ele chamou de livre "territorialização do capital". No contexto de pouco questionamento, em virtude da ditatura militar, permitiu-se o início da profunda transformação do Cerrado:

\footnotetext{
${ }^{5}$ De acordo com Arrais (2007) a Marcha para o Oeste consiste em programas do governo federal que tinham como objetivos o protagonismo na produção do território e a diminuição das desigualdades regionais. O mesmo foi dividido em duas etapas: $1^{\circ}$ Expedição Roncador Xingu (1943 - 1949) - que partiu de Aruanã com destino ao Pará e tinha como objetivos: interesses militares e a ocupação da vertente oeste da Bacia do Rio Araguaia; $2^{\circ}$ Fundação Brasil Central (1943 - 1967), está interviu no território goiano, estimulando a colonização.

Estudos Geográficos, Rio Claro, 17: 193-204, jan./jun. $2019 \quad$ (ISSN 1678-698X) http://www.periodicos.rc.biblioteca.unesp.br/index.php/estgeo
} 
As transformações espaciais decorrentes dessas investidas culminaram em novas paisagens nas áreas cerradeiras. Da pecuária extensiva, da agricultura tradicional e camponesa restou muito pouco, pois a agropecuária moderna, com os maiores índices de produção e produtividade do país, expulsou as "velhas" formas de uso e exploração da terra para as áreas de fronteiras, para as áreas urbanas e/ou para os fundos de vales que se tornaram refúgios para os camponeses e trabalhadores da terra desterritorializados. Em Goiás, a (re)arrumação espacial se efetivou a partir da desagregação dos tradicionais ocupantes de terras que, em sua maioria, se dedicavam à pecuária extensiva. Com a expulsão dos camponeses e trabalhadores da terra que praticavam a agricultura camponesa, 0 direito de usufruto passou àqueles que possuíam capital financeiro e experiência acumulada, vindos do sul do país, onde a agricultura moderna se iniciara a partir da década de 1950. (MENDONÇA, 2004, p. 28).

Em algumas regiões de Goiás, como Sudoeste Goiano, essas séries de mudanças ocorreram em um curto espaço de tempo, começando na década de 1970 e "consolidando" entre os anos de 1997 a 2008, quando se "instala na região - Complexo Agroindustrial (CAI), responsável por toda uma cadeia produtiva de grãos, aves e suínos, trabalhando através de um sistema integrado" (PIZARRO, 2017 - pp. 3 - 4).

O processo histórico de ocupação do Cerrado Goiano e as mudanças ocorridas como a modernização da agricultura, foram amplamente estudados em diversos artigos, teses e dissertações (PEIXINHO, 2002; TEIXEIRA NETO, 2002; MENDONÇA, 2004; BORGES, 2007 e 2016; ARRAIS, 2007; LIMA E CHAVEIRO, 2010; FREITAS e CHAVEIRO, 2011; BORGES, 2013; SILVA, 2013). É fundamental verificar a transformação das formas de ocupação do território, sobretudo a partir da década de 1970, com o avanço da ocupação do Cerrado como uma nova fronteira agrícola, conforme destaca Frederico (2011):

Denomina-se fronteira agrícola moderna as áreas ocupadas, a partir da década de 1970, por monoculturas intensivas em capital e tecnologia, em substituição à vegetação original (principalmente de Cerrado), a culturas tradicionais (praticadas por campesinos e/ou agricultores familiares) $\mathrm{e}$ as áreas de pastagens extensivas (FREDERICO, 2011 - p. 06).

Nesse artigo não pretende se debruçar sobre a história de ocupação do Cerrado Goiano, mas é importante destacar o tempo de maturação das relações sociais de Goiás sobre um vasto território de Cerrado, marcadas pela autosufiência em decorrência do isolamento geográfico e posteriormente pela rápida transformação do território a partir da década de 70 .

Para Pelá e Mendonça (2010) o processo de ocupação do Cerrado goiano no século $X X$ afetaram não apenas as riquezas materiais, assinalando a importância da sociodiversidade:

A compreensão de que o olho que olha implica o objeto olhado nos faz conceber o olhar integrado, considerando que os efeitos dos impactos gerados no processo de ocupação do Cerrado goiano, no

\footnotetext{
${ }^{6}$ Não se trata de afirmar que o processo cessou, mas chegou a um patamar que se apresenta nos dias atuais.

Estudos Geográficos, Rio Claro, 17: 193-204, jan./jun. 2019 (ISSN 1678-698X) http://www.periodicos.rc.biblioteca.unesp.br/index.php/estgeo
} 
século $\mathrm{XX}$, afetaram as riquezas materiais e imateriais. Parte-se do entendimento de que o Cerrado não é composto apenas de biodiversidade, mas também da sociodiversidade e que, por conseguinte, não foram apenas as suas riquezas naturais $e$ biológicas que sofreram alterações, mas a cultura e a memória dos povos que ali habitavam. (PELÁ e MENDONÇA, 2010, p. 56).

Para Mazzetto e Silva (2009) todo esse processo narrado como de transformação do Cerrado, sobretudo com a instalação do CAl demonstra as contraditoriedades da civilização ocidental:

O processo em curso no Cerrado brasileiro mostra todas as mazelas do que a civilização ocidental vem chamando de desenvolvimento. Parece ser emblemático aqui o caráter essencial do vocábulo - é rompendo com o envolvimento do lugar, dos povos com seu ambiente, que se faz o desenvolvimento no Cerrado. É rompendo com a sociobiodiversidade que se constrói o (agro)negócio da monocultura-commodity. É expropriando as comunidades locais e implantando estruturas transnacionais que o lugar se torna mercadoria para o circuito global. É tirando os cerrados tortos das chapadas e substituindo-os por paisagens uniformes-industriais que a caixa d'água é desmontada e os rios, córregos e nascentes deixam de alimentar as famílias e as bacias hidrográficas estratégicas para o país. A manutenção da vida do Cerrado brasileiro depende de muita resistência das comunidades, muita articulação entre elas e da viabilização de novas configurações, ordenamentos territoriais/ambientais que deem suporte ao processo de reenvolvimento local, fortalecendo as territorialidades tradicionais do Sertão - as portadoras da cultura da convivência e da sustentabilidade (MAZZETTO e SILVA, 2009, p. 106).

A realidade que vem se construindo após 1970 não é de um Cerrado "em pé" e as populações tradicionais que nele sobrevivem ficarem restritas as áreas de menor interesse ao capital do CAl, áreas de relevo mais acentuado e de solos menos propicio ao cultivo de soja, milho e algodão. Essas áreas se tornaram enclaves $^{7}$ de Cerrado no Estado de Goiás e nelas estão a Sociobiodiversidade, remanescentes desse Bioma.

As áreas de menor interesse do CAI é quem passar a despertar o interesse dos grupos econômicos que passam a investir na geração de energia através da construção de PCHs a partir dos anos 2000. É justamente essas áreas que concentram as populações tradicionais, ribeirinhos, quilombolas.

Para entender esse processo e como os empreendimentos (obras de $\mathrm{PCH}$ ) são ancorados na opinião pública nos baseamos na discussão sobre paradigma da adequação versus paradigma de sustentabilidade de Zhouri e Oliveira (2007).

No "paradigma da adequação", a obra assume lugar central, apresentando-se de forma inquestionável e inexorável. Nesta concepção, o ambiente é percebido como externalidade, paisagem que deve ser modificada e adaptada aos objetivos do projeto técnico.

\footnotetext{
${ }^{7} \mathrm{O}$ termo enclave de Cerrado é usado para designar "refúgios" de Cerrado em meio a floresta amazônica e ou em porções mais distantes da área "core" do Cerrado no centro do Brasil. Considerando que resta pouco do Cerrado em Goiás, os remanescentes tornam-se enclaves ao meio da grande lavoura do Complexo Agroindustrial.
Estudos
Geográficos
Rio Claro, 17:
193-204,
jan./jun.
2019
(ISSN
$1678-698 X)$

http://www.periodicos.rc.biblioteca.unesp.br/index.php/estgeo
} 
Nesse processo, arranjos e ajustes tecnológicos dados por medidas mitigadoras e compensatórias cumprem a função de adequação. Com efeito, a "necessidade" e a viabilidade socioambiental da obra não são colocadas em pauta. Em oposição a esse modelo, o paradigma da sustentabilidade coloca em discussão os padrões de produção e consumo que reclamam pela obra, os interesses e valores sociais que estão envolvidos em sua construção e seus reais beneficiários. Nesse sentido, o paradigma da sustentabilidade exige uma análise efetiva acerca da viabilidade socioambiental da obra, contemplando as potencialidades do ambiente em que ela se insere e sua relação com os usos e significados atribuídos ao território no local. (ZHOURI e OLIVEIRA, 2007, p. 122).

Como dissemos, as PCHs espalharam-se pela maioria dos estados da federação e as consequências são as mesmas. Silva e Sato (2012, p. 10) argumentam que "nos espaços que se estabelecem os conflitos socioambientais não estão em disputas apenas os bens e serviços ecossistêmicos, mas, também, as formas distintas de apropriação do território". Nos mesmo artigo (SILVA e SATO, op cit) avaliam as consequências das instalações de PCHs nos rios do Estado de Mato Grosso - MT:

Somando a este cenário MT ainda garante o posto de ser o segundo Estado em instalações de empreendimentos como as pequenas centrais hidrelétricas (PCH). A escolha em gerar energia com pequenas centrais justifica-se pela não necessidade de se realizar Estudos de Impactos Ambientais (EIA), o que é exigido no caso de usinas hidrelétricas (UHE), facilitando desta forma o processo de licenciamento ambiental. Entretanto, os impactos cumulativos provocados pela instalação de diversas $\mathrm{PCH}$ em um mesmo rio são, muitas vezes, tão ou mais intensos que os gerados pelas UHE (SILVA e SATO, 2012, p. 13).

"O aumento dos conflitos no campo envolvendo água é um dos principais indicadores das profundas e contraditórias transformações em curso na geografia social brasileira (e mundial)" (PORTO-GONÇALVES et. al., 2018, p. 37).

Para Chaveiro (2005) a modernização foi/é avassaladora, mas a tradição sem mantém, o que nós chamamos de sociobiodiversidade.

(...) é necessário sintetizar que a modernização apesar de ser avassaladora e hegemônica não erradicou a tradição; e que embora resistindo não se impõe. Mesmo que não se imponha, ora converge, ora conflita, ora se adapta aos novos signos modernizantes. (CHAVEIRO, 2005, p. 53).

Essa nova forma de disputa pelo território, cuja a construção de PCHs está no centro do embate, é uma ameaça que pode castigar o restante das populações que resistem no campo e colocar "debaixo da d'água" os remanescentes de cerrado e sua sociobiodiversidade.

Estudos Geográficos, Rio Claro, 17: 193-204, jan./jun. $2019 \quad$ (ISSN 1678-698X) http://www.periodicos.rc.biblioteca.unesp.br/index.php/estgeo 


\section{A PERDA DA TERRA, DA "VIDA": O CASO DA PCH SANTO ANTÔNIO DO CAIAPÓ}

A proposta de análise crítica dos eventos associados a construção e operação da $\mathrm{PCH}$, supra citada, se baseia em relatos de moradores atingidos e de trabalho de campo realizado na área. Não existe a identificação de nomes e/ou propriedades atingidas pela construção da barragem e formação do reservatório da $\mathrm{PCH}$, contribuindo para a preservação da imagem e identidade dos atingidos.

A área do lago da PCH Santo Antônio, a barragem e a estrutura da casa de máquinas (turbinas) prejudicaram 30 proprietários de terra, a maioria pequenas propriedades nos três municípios limítrofes - Arenópolis, Ivolândia, e Palestina de Goiás, dentre essas trinta famílias, 7 foram desapropriadas judicialmente. Algumas famílias perderam $90 \%$ de suas áreas.

Entre as famílias entrevistadas, sete no total, é comum o relato de insatisfação com a situação, a maioria morava a muitos anos no local (figura 1), passando a propriedade e suas benfeitorias por várias gerações. Por ser uma área onde o rio está encaixado no relevo, grande parte das famílias moravam nas áreas mais baixas, propiciando a formação da roça e da horta, além da construção da moradia - essas foram as áreas mais atingidas, a maioria das famílias perderam vossas casas, construídas ao longo de uma ou mais gerações.

O enraizamento de sentimentos, e a incorporação da cultura local, segundo Foetsch (2005 p. 64), contribuem para a formação da identidade de lugar; e, esse sentido de identidade envolve percepção, se apresenta carregado de satisfação, reminiscência e felicidade, como um somatório das dimensões simbólicas ao encarar as experiências banais e aspirações humanas.

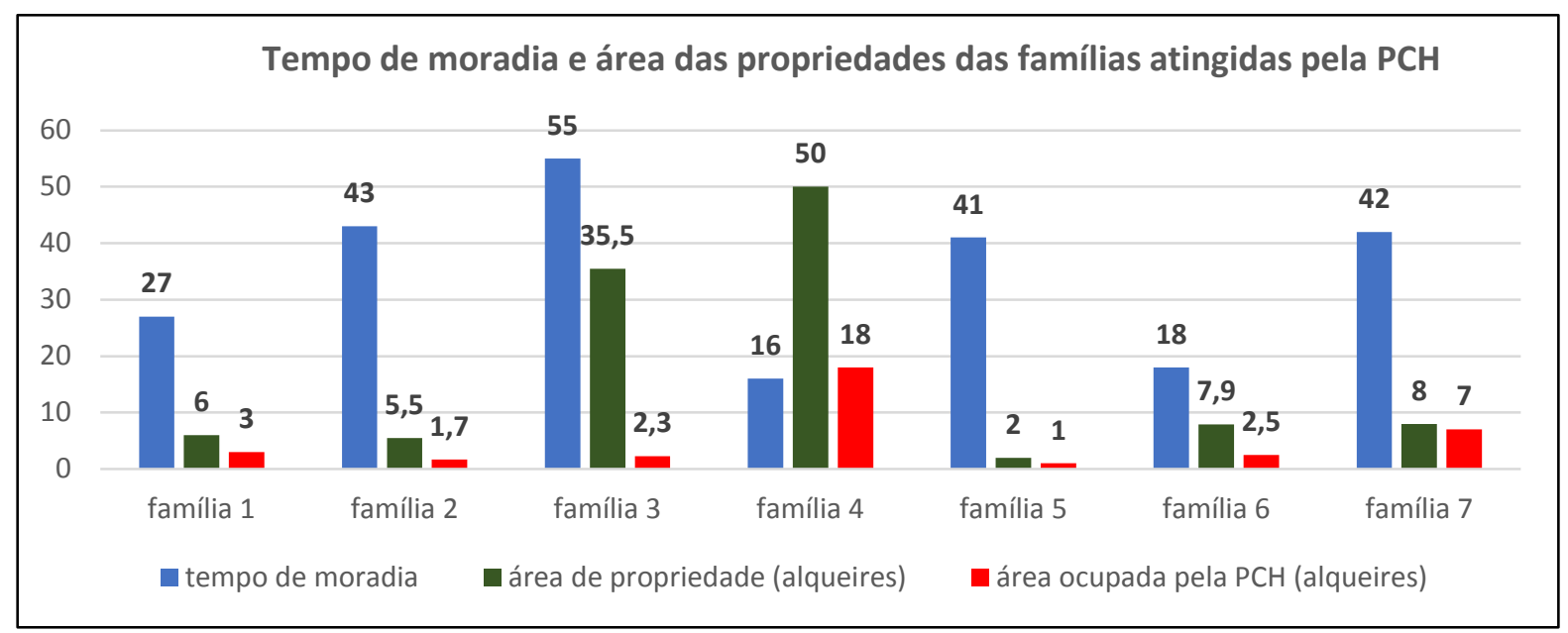

Figura 1 - Tempo de moradia na propriedade afetada pela PCH

Fonte: dados obtidos através do trabalho de campo, com parte das famílias atingidas pela construção da $\mathrm{PCH}$. Valdir Specian e Sabrina Carlindo (2015).

\section{ENTRE O IMAGINÁRIO (PROPOSTO) E A REALIDADE DOS PROGRAMAS DE ASSISTÊNCIA AOS ATINGIDOS}

Os documentos oficiais associados a obra da PCH Santo Antônio do Caiapó: EIA/RIMA e Programas de Apoio aos Atingidos, previam uma série de ações para minimizar as perdas das famílias atingidas pela construção da $\mathrm{PCH}$ e a formação do Estudos Geográficos, Rio Claro, 17: 193-204, jan./jun. 2019 (ISSN 1678-698X) http://www.periodicos.rc.biblioteca.unesp.br/index.php/estgeo 
lago da usina. O quadro 1 apresenta que parte do proposto ficou apenas no imaginário dos responsáveis pela obra, a realidade dos moradores, constatada no trabalho de campo, é totalmente distinta.

\begin{tabular}{|c|c|}
\hline $\begin{array}{l}\text { Condições apresentas no } \\
\text { plano de apoio aos atingidos } \\
\text { pelo empreendimento. }\end{array}$ & $\begin{array}{l}\text { Condições constatadas no trabalho de campo e } \\
\text { relatadas pelas famílias afetadas. }\end{array}$ \\
\hline $\begin{array}{l}\text { Indenização pela terra } \\
\text { benfeitorias } \\
\begin{array}{l}\text { (pagamento } \\
\text { dinheiro) aos proprietários. }\end{array}\end{array}$ & $\begin{array}{l}\text { As famílias fizeram muitas reclamações, principalmente sobre as } \\
\text { indenizações feitas pelas benfeitorias, segundo relatos, não } \\
\text { houve nenhuma valorização das benfeitorias existentes. }\end{array}$ \\
\hline $\begin{array}{l}\text { O Programa Básico Ambiental } \\
\text { (PBA) deve ser especifico, pois } \\
\text { deve ser elaborado com o escopo } \\
\text { de não prejudicar as pessoas } \\
\text { afetadas pelas obras e } \\
\text { funcionamento. }\end{array}$ & $\begin{array}{l}\text { Segundo eles em nenhum momento foi demostrado importância } \\
\text { ou preocupações com as famílias, com suas histórias de vida que } \\
\text { cada um tinha com a terra, não levaram em consideração nada, } \\
\text { apenas a construção da "usina". }\end{array}$ \\
\hline $\begin{array}{l}\text { Possibilitar a sua recuperação } \\
\text { econômica e a eventual } \\
\text { adaptação social de cada família } \\
\text { afetada e também desapropriada. }\end{array}$ & $\begin{array}{l}\text { Essas famílias nunca receberam nenhum tipo de suporte } \\
\text { econômico ou social ou até mesmo instruções que os } \\
\text { facilitassem nessa nova fase de adaptação física, social e até } \\
\text { mesmo psicológica. }\end{array}$ \\
\hline $\begin{array}{l}\text { O PBA traz como um de seus } \\
\text { objetivos a indenizações das } \\
\text { benfeitorias de forma correta, } \\
\text { legal e justa. }\end{array}$ & $\begin{array}{l}\text { O correto, legal e justo ficou apenas nos papéis, pois para essas } \\
\text { famílias, o que ouvimos foram críticas e mais críticas, como; } \\
\text { destruição, transtornos, prejuízos, perdas. Ouvimos de famílias } \\
\text { que disseram perder até mesmo sua dignidade. }\end{array}$ \\
\hline $\begin{array}{l}\text { O PBA tem como meta oferecer } \\
\text { aos proprietários atingidos as } \\
\text { condições iguais ou, se possível, } \\
\text { melhores que as anteriores. }\end{array}$ & $\begin{array}{l}\text { Disseram que as equipes da PCH chegaram nas propriedades de } \\
\text { uma hora pra outra, afirmando que utilizariam parte de suas } \\
\text { terras, e que os mesmos eram obrigados a vender, e ainda que } \\
\text { os reabilitariam em localidades e situações iguais, ou até } \\
\text { melhores que as de antes. Foram encontradas situações de } \\
\text { famílias que ficaram totalmente desapropriadas, que colocaram } \\
\text { suas coisas em meia pastagem, e tiveram que se virar com seus } \\
\text { próprios meios, os deixaram sem qualquer tipo de amparo, até } \\
\text { mesmo sem água, sem luz, sem moradia, sem dignidade alguma. }\end{array}$ \\
\hline $\begin{array}{llr}\text { Plantio de } & \text { espécies nativas } \\
\text { pioneiras, } & \text { segundarias } & \text { e } \\
\text { climáticas, } & \text { conduzidos } & \text { de } \\
\text { maneira adequada e favorecendo } \\
\text { o desenvolvimento r das } \\
\text { mudanças. }\end{array}$ & $\begin{array}{l}\text { A usina começou a funcionar no segundo semestre de } 2012 \text {, } \\
\text { esses dados foram coletados no fim de } 2015 \text {, e não podemos ver } \\
\text { nunca árvore plantada pelo pessoal responsável pelo } \\
\text { reflorestamento das margens do lago, todos sabem que esse } \\
\text { reflorestamento é uma obrigação a ser cumprida, e já se } \\
\text { passaram mais de três anos que começaram a implantação da } \\
\text { PCH. }\end{array}$ \\
\hline $\begin{array}{l}\text { As benfeitorias antigas, no caso } \\
\text { de construções ou equipamentos, } \\
\text { serão indenizadas, reconstruídas } \\
\text { ou recolocadas no próprio terreno } \\
\text { do proprietário. }\end{array}$ & $\begin{array}{l}\text { Não levaram em conta nem as casas, muito menos as } \\
\text { benfeitorias antigas, que segundo os responsáveis pela } \\
\text { negociação, todas consideradas inutilizáveis e sem nenhum valor } \\
\text { econômico. }\end{array}$ \\
\hline $\begin{array}{l}\text { Deverão merecer atenção } \\
\text { especial e serão indenizadas } \\
\text { dentro de um critério diferenciado, } \\
\text { as famílias que possuam chefes } \\
\text { aposentados ou tenham idade } \\
\text { avançada e ainda sofram de } \\
\text { alguma doença que não permita o } \\
\text { trabalho. }\end{array}$ & $\begin{array}{l}\text { Critérios diferenciados? Quais? Porque nem os suportes básicos } \\
\text { os deram, como instalações de água e energia. Depois que foram } \\
\text { desapropriados de suas casas, nunca mais receberam nem um } \\
\text { tipo de ajuda ou como chamam eles "suporte", hoje têm relatos } \\
\text { de famílias que construíram suas casas com seus próprios meios } \\
\text { nos pequenos terrenos que os sobraram, se quiseram energia } \\
\text { em suas casas tiveram que correr atrás e pagar por sua } \\
\text { instalação, idem para a regularização do acesso a água. E isso } \\
\text { com representantes de famílias com idades superiores há } 60 \\
\text { anos. }\end{array}$ \\
\hline
\end{tabular}

Quadro 1 - Correlação entre o previsto nos programas de apoio aos atingidos e a realidade constatada

Fonte: Documentação publica oficial da $\mathrm{PCH}$ e entrevistas com moradores atingidos pelo empreendimento (2015). Organizada pela autores.

Estudos Geográficos, Rio Claro, 17: 193-204, jan./jun. 2019 (ISSN 1678-698X) http://www.periodicos.rc.biblioteca.unesp.br/index.php/estgeo 
O quadro 1 é apenas um resumo do que foi constatado na pesquisa. De maneira geral as famílias atingidas tiveram que procurar apoio junto aos vizinhos. A adaptação as novas condições é lenta e sem o devido apoio dos responsáveis pelo empreendimento.

\section{CONSIDERAÇÕES FINAIS}

A geração de energia elétrica é necessária, considerando o seu uso múltiplo e garantia de qualidade de vida para a sociedade, ainda que muitos brasileiros não conseguem ter acesso a esse bem. O modelo energético brasileiro não pode ser considerável sustentável como apresentado pelo estado e pela mídia, tampouco é poluidor como outras fontes de recursos não renováveis que compõem a matriz energética de muito países - sobretudo os modelos baseados no uso de combustíveis fósseis.

As PCHs, foco de artigo, entraram na pauta política nacional em um momento de crise de abastecimento. A ideia de ser menos impactante que as grandes usinas hidrelétricas (UHE) só pode ser considerada na particularidade de cada empreendimento, mesmo por que a área alagada é menor. A questão é que as $\mathrm{PCH}$ se multiplicam, quase se sobrepondo umas a outras nas bacias interiores e, dessa forma, multiplicando os impactos na forma de acumulação.

O agravante é que o processo de licitação desse tipo de empreendimento foi "relaxado", permitindo a rapidez da instalação. Os empreendimentos contam ainda com a omissão dos órgãos ambientais estaduais, responsáveis pela fiscalização, muitas vezes faltam pessoal e recursos para fiscalização. Os atingidos por PCHs acabam silenciados, o número de famílias afetadas em cada empreendimento é pequeno para fazer ecoar na sociedade o seu sofrimento. Outro fator importante é uso das mídias locais para fazer referência as benesses dos empreendimentos, da geração de emprego a proteção ambiental, os temas mostram os possíveis benefícios das PCHs. É necessário rever as regras de instalação e operação de $\mathrm{PCHs}$ e ainda rever qualificação desse tipo de empreendimento como de baixo impacto socioambiental.

\section{REFERÊNCIAS}

ANEEL. Agência Nacional de Energia Elétrica. Banco de Informações de Geração. Disponível em: <www.aneel.gov.br>. Acesso em: 12 jan. 2017.

ARRAIS, Tadeu P. A. O Território Goiano: uma abordagem quase contemporânea do desenvolvimento regional. In: ENCONTRO DA ASSOCIAÇÃO NACIONAL DE PÓS-GRADUAÇÃO E PESQUISA EM PLANEJAMENTO URBANO E REGIONAL, 12., 2007, Belém. Anais..., 2007. p. 1 - 21. Disponível em: $<$ https://observatoriogeogoias.iesa.ufg.br/p/2340-artigos $>$. Acesso em: 03/03/2018.

BORGES, Júlio Cesar Pereira. O Estado e as políticas públicas: trilhos, estradas, fios e genes da modernização do território goiano. 2007. 116 f. Dissertação (Mestrado em Geografia) - Instituto de Estudos Sócio-Ambientais, UFG, Goiânia, 2007. Disponível em : <https://repositorio.bc.ufg.br/tede/handle/tde/1861>. Acesso em: 03/03/2018.

Estudos Geográficos, Rio Claro, 17: 193-204, jan./jun. 2019 (ISSN 1678-698X) http://www.periodicos.rc.biblioteca.unesp.br/index.php/estgeo 
BORGES, Júlio C. P. FAZENDA-ROÇA GOIANA: matriz espacial do território e do sertanejo goiano. Goiânia. 2016. 195 f. Tese (Doutorado em Geografia) Instituto de Estudos Sócio-Ambientais, UFG, Goiânia, 2016. Disponível em: < https://repositorio.bc.ufg.br/tede/handle/tede/5853>. Acesso em: 27/12/2017.

BORGES, ROSANA M. R. Pensamentos Dispersos, Hegemonias Concentradoras: discursos jornalísticos e movimentos de territorialização no cerrado. 2013. 421 f. Tese (Doutorado em Geografia) - Instituto de Estudos SócioAmbientais, UFG, Goiânia, 2013. Disponível em: < https://repositorio.bc.ufg.br/tede/handle/tede/3697. Acesso em: 23/03/2018.

BRASIL. Decreto Lei no 5.025, de 30 de março de 2004. Regulamenta o inciso I e os $\S \S 1^{\circ}, 2^{\circ}, 3^{\circ}, 4^{\circ}$ e $5^{\circ}$ do art. $3^{\circ}$ da Lei $n^{\circ} 10.438$, de 26 de abril de 2002 , no que dispõem sobre o Programa de Incentivo às Fontes Alternativas de Energia Elétrica PROINFA, primeira etapa, e dá outras providências. Disponível em: http://www.planalto.gov.br/ccivil 03/ ato2004-2006/2004/decreto/d5025.htm>.

Acesso em 22 de outubro de 2017.

CHAVEIRO, Eguimar F. Símbolos das Paisagens do Cerrado Goiano. In: ALMEIDA, M. G. de (Org). Tantos Cerrados: Múltiplas abordagens sobre a biogeodiversidade e singularidade cultural. Goiânia: Vieira, 2005, p.47-62.

FOETSCH, Alcimara Aparecida. Subsídios Teóricos epistemológicos para um operacional estudo do lugar. Revista Espaço Acadêmico, n. 55, dez. 2005.

FREDERICO, Samuel. As cidades do agronegócio na fronteira agrícola moderna brasileira. Caderno Prudentino de Geografia, Presidente Prudente, v. 1, n. 33, pp. 5-23, jan.jul., $2011 . \quad$ Disponível em: <http://revista.fct.unesp.br/index.php/cpg/article/view/1933>. Acesso em: 27/12/2017.

FREITAS, Weder D. e CHAVEIRO, Eguimar F. Cerrado: modernização e ocupação a partir da localidade. Revista Geográfica de América Central, Costa Rica. Número especial EGAL - 2011. pp. 1 - 16, 2011. Disponível em: <http://www.revistas.una.ac.cr/index.php/geografica/article/view/2612>. Acesso em: 05/01/2018.

LIMA, Sélvia C. de; CHAVEIRO, Eguimar F. O Cerrado Goiano Sob Múltiplas Dimensões: Um território perpassado por conflitos. Espaço em Revista: Universidade Federal de Goiás, Catalão, v. 12, n. 2, pp. 66 - 83, 2010. Disponível em: $\quad<$ https://www.revistas.ufg.br/espaco/article/view/16857>. Acesso em: 05/01/2018.

MAZZETTO SILVA, Carlos E. Ordenamento Territorial no Cerrado brasileiro: da fronteira monocultora a modelos baseados na sociobiodiversidade. Desenvolvimento e Meio Ambiente, Curitiba, Editora UFPR, n. 19, p. 89-109, jan./jun. 2009. Disponível em: < https://revistas.ufpr.br/made/article/view/16407>. Acesso em: 12 abr. 2019.

MENDONÇA, Marcelo R. A Urdidura Espacial do Capital e do Trabalho no Cerrado do Sudeste Goiano. Presidente Prudente. 2004. 458 f. Tese

Estudos Geográficos, Rio Claro, 17: 193-204, jan./jun. 2019 (ISSN 1678-698X) http://www.periodicos.rc.biblioteca.unesp.br/index.php/estgeo 
(Doutoramento em Geografia) - Universidade Estadual Paulista, Presidente Prudente, 2004.

PEIXINHO, Dimas M. O Processo de Ocupação dos Cerrados. Temporis (ação): Universidade Estadual de Goiás, Cidade de Goiás, v. 01, pp. 201 - 230, 2002.

PELÁ, Márcia; MENDONÇA, Marcelo R. Cerrado Goiano: encruzilhada de tempos e territórios em disputa. In: PELÁ, Márcia; CASTILHO, Denis (Org.). Cerrados: perspectivas e olhares. Goiânia: Ed. Vieira, 2010, p. 51 - 70. Disponível em: $<$ https://laboter.iesa.ufg.br/up/214/o/Livro CERRADOS perspectivas e olhares.pdf >. Acesso em: 17 de abr. 2019.

Pequenas centrais hidrelétricas ameaçam populações tradicionais do Vale do Ribeira. Instituto Socioambiental. São Paulo, 13 de mar. de 2018. Disponível em: https://www.socioambiental.org/pt-br/noticias-socioambientais/pequenas-centrais-

hidreletricas-ameacam-populacoes-tradicionais-no-vale-do-ribeira. Acesso em $\underline{29 / 01 / 2019}$.

PIZARRO. Roberto E. C. O agronegócio e a produção do espaço da região de planejamento sudoeste goiano. 2017. 347 f. Tese (Doutorado em Geografia) Universidade de Brasília, Brasília, 2017. Disponível em: $<$ http://repositorio.unb.br/handle/10482/25331? mode=full> Acesso em: 09/01/2018.

PORTO-GONÇALVES, Carlos W.; CUIN, Danilo P.; LADEIRA, Julia N.; SILVA, Marlon N.; LEẪO, Pedro C. da R. A contra reforma agrária na lei e na marra - Brasil (2015-2017). In: Conflitos no Campo - Brasil 2017. Goiânia: CPT Nacional, 2018. p. 26 - 48. Disponível em: < https://cptnacional.org.br/>. Acesso em: 10/05/2019.

SILVA, ELAINE B. da. A dinâmica socioespacial e as mudanças na cobertura e uso da terra no bioma Cerrado. 2013. 109 f. Tese (Doutorado em Geografia) Instituto de Estudos Sócio-Ambientais, UFG, Goiânia, 2013. Disponível em: <https://repositorio.bc.ufg.br/tede/handle/tede/3277>. Acesso em: 20/03/2018.

TEIXEIRA NETO, ANTÔNIO. O Território Goiano: formação e processo de povoamento e urbanização. In: ALMEIDA, M. G. (Org.). Abordagens geográficas de Goiás: o natural e o social na contemporaneidade. Goiânia: UFG, 2002. p. 1146.

SILVA, Michelle J. da; SATO, Michèle T. Territórios em tensão: o mapeamento dos conflitos socioambientais do Estado de Mato Grosso - Brasil. Ambiente e Sociedade, São Paulo, v. XV, n. 1, pp. 01 - 28, jan./abr., 2012. Disponível em: $<$ http://www.scielo.br/pdf/asoc/v15n1/02.pdf>. Acesso em: 10/05/2019.

ZHOURI, Andréa; OLIVEIRA, Raquel. Desenvolvimento, Conflitos Sociais e Violência no Brasil Rural: o caso das usinas hidrelétricas. Ambiente e Sociedade, São Paulo, v. X, n. 2, pp. 119 - 135, jul./dez., 2007. Disponível em: < http://www.scielo.br/pdf/asoc/v10n2/a08v10n2.pdf>. Acesso em: 10/05/2019.

Estudos Geográficos, Rio Claro, 17: 193-204, jan./jun. 2019 (ISSN 1678-698X) http://www.periodicos.rc.biblioteca.unesp.br/index.php/estgeo 